\title{
CARACTERIZACIÓN DE LAS FERIAS FRANCAS DE PRODUCTORES AGROPECUARIOS EN LA PROVINCIA DE CÓRDOBA (ARGENTINA)
}

\author{
Ferrer, G. ${ }^{1 ;}$ Barrientos, M. $^{1}$ \& SAal, G. ${ }^{1}$
}

\section{RESUMEN}

Una Feria Franca de productores agropecuarios es un espacio de comercialización minorista organizado por productores familiares. Las ferias francas de alimentos constituyen una buena opción, tanto a los consumidores conscientes, como a los productores familiares que buscan una alternativa de comercialización más sustentable. Enfocando nuestro interés en estos procesos, formulamos la siguiente pregunta ¿Cuáles son las principales características que distinguen las ferias francas de productores en la provincia de Córdoba (Argentina)? La sistematización de las 12 ferias que participaron de la investigación, estuvo basada en tres criterios (tipo preponderante de productos ofrecidos, tamaño y diversidad), que permite realizar una caracterización rápida y eficiente de sus principales rasgos. Se han encontrado dos posiciones en disputa ante los procesos organizativos: la asamblearia, que privilegia una posición individualista de los feriantes y confía en la selección/ regulación que pueden hacer los compradores y la formalizante, que propicia la organización en comisiones internas y reglar el comportamiento de los feriantes.

Palabras claves: Comercialización de agricultores, agricultura familiar, agroecología, organización de productores, Economía social.

\section{ABSTRACT}

\section{Characterization of Farmers Markets in the Province of Córdoba (Argentina).}

A farmers market is a retail marketplace organized by family farmers. They are a good alternative both for conscious consumers and family farmers who search for more sustainable trade practices. Focusing our interest on these processes, we aimed to know which are the main features characterizing farmers markets in the Province of Córdoba (Argentina). The systematization of the 12 fair markets that took part of the research was based on three main criteria: type of goods offered, market size, and diversity. This allowed to produce a rapid and efficient characterization of their main features. Regarding organizational processes, two positions in dispu-

1.- Departamento de Desarrollo Rural, Facultad de Ciencias Agropecuarias (UNC). Ing. Agr. Félix Aldo Marrone 746. Ciudad Universitaria. CC 509. (5000) Córdoba. Tel.: (0351) 4334103. Email: guillermoferre@ gmail.com

Manuscrito recibido el 12 de noviembre de 2015 y aceptado para su publicación el 6 de mayo de 2016. 


\section{G. Ferrer et al.}

te where found. A more individualistic assembly-prone position, where farmers rely on consumers' ability to select and regulate who to buy goods from, and a formalizing one that fosters organization and the creation of internal commissions to regulate sellers' behaviour.In FR significant difference was found between treatments. The C group had $18 \%$ fewer FR that T. An interaction between treatment and was detected to date in FR $(p<0.05)$ on days whose ITH was> 84. The animals in group $\mathrm{C}$ remained $10 \%$ less time in the shade that predominate $\mathrm{T}$ behavior was to stop. The animals in the traditional group were $60 \%$ longer than the comfort panting. Key words: Farmers market, famiily farming, agroecology, farmers'organization, social economy

\section{INTRODUCCION}

Una Feria Franca de productores es un espacio de comercialización organizado de los productores familiares que genera un impacto socio- económico y cultural en las unidades de producción, en el núcleo de las familias feriantes y en las localidades donde se realizan (5). Se diferencian de las ferias francas tradicionales porque los puesteros son, a su vez, los productores y pueden responder por la calidad de sus productos. Algunas ferias, dando especial énfasis a la calidad, se auto imponen comercializar sólo productos agroecológicos, lo que implica que no han sido tratados con agro tóxicos y que provienen de unidades de producción familiares locales.

Las ferias francas constituyen el encuentro de dos actores fundamentales; los consumidores de alimentos y los productores. Consideraremos a continuación, cada uno de ellos:

Los demandantes o consumidores: Porciones crecientes de la población de muchos países, comienzan a valorar positivamente aquellos alimentos vegetales que no sólo le proporcionan los nutrientes indispensables para la vida (hidratos de carbono, proteínas, vitaminas, etc.), sino que, además, poseen sustancias con un posible efecto protector (12), al objetivar la relación entre alimento y salud.
En el mundo y en Argentina particularmente, el consumo de verduras presenta dos aspectos problemáticos, el cuantitativo que refleja un escaso consumo y el cualitativo, dado que los productos vegetales que en general se consumen estarían contaminados con productos agro tóxicos (2).

La recomendación de la Organización Mundial de la Salud es consumir dos porciones de frutas y tres de verduras por día (10). Según datos de la 2da. Encuesta Nacional de Factores de Riesgo (ENFR), sólo el 4,8\% de la población argentina consume al menos las cinco porciones diarias de frutas y verduras recomendadas, siendo el promedio de consumo por habitante inferior a 2 porciones por día (9).

En relación a la calidad, existe una desconfianza sobre la inocuidad de los productos que se obtienen con la agricultura industrial, lo cual se va confirmando con la aparición de publicaciones que sostienen que muchos de los alimentos que son consumidos en el país están contaminados con agrotóxicos y generan enfermedades $(2 ; 1)$.

Ambos aspectos se potencian, ya que por un lado, la campaña de los organismos de salud y, por otro, el discurso crítico sobre la comida chatarra y productos agrícolas contaminados, van generando un grupo creciente de población concientizada que demanda frutas y verduras sanas, sin contaminantes tóxicos.

Revista FAVE - Ciencias Agrarias 15 (1) 2016 